Supplement of Hydrol. Earth Syst. Sci., 18, 5025-5040, 2014

http://www.hydrol-earth-syst-sci.net/18/5025/2014/

doi:10.5194/hess-18-5025-2014-supplement

(C) Author(s) 2014. CC Attribution 3.0 License.

(c) (i)

Supplement of

\section{A virtual water network of the Roman world}

\section{B. J. Dermody et al.}

Correspondence to: B. J. Dermody (brianjdermody@gmail.com)

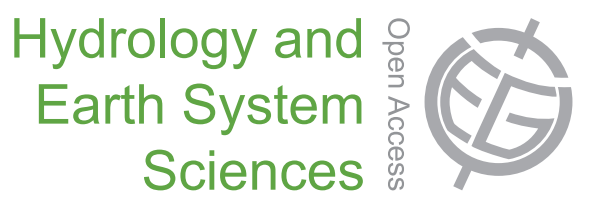

\author{
Conspondence to. B. J. Dermody (brianjdernody@gmail.com)
}




\section{Supplement}

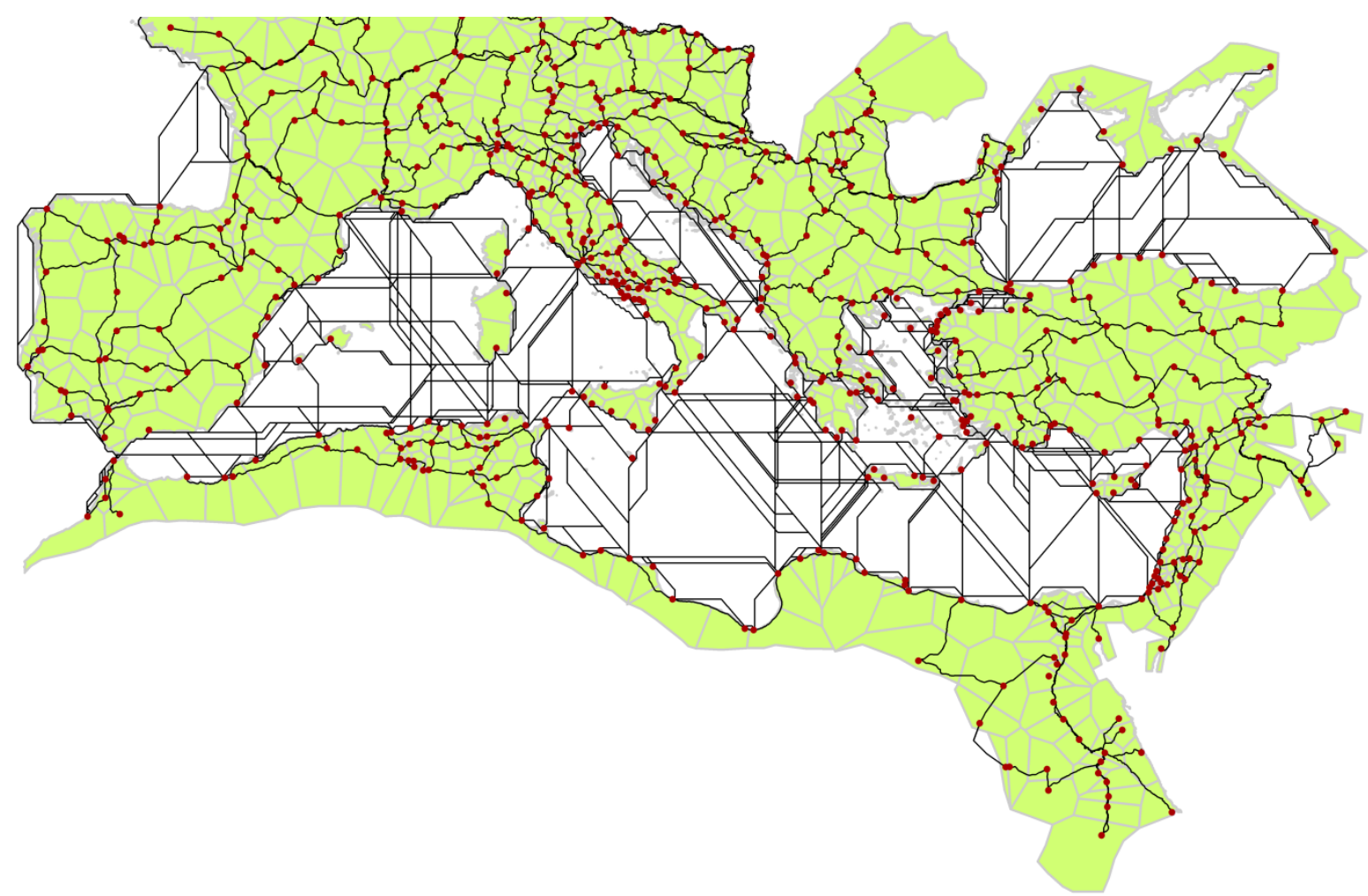

Figure S1. Orbis network and city regions. The red dots are cities in our network and the black lines are the trade links between cities. A Theissen polygon operation was carried out between cities to define each city region. The sum of virtual water surpluses and deficits in each city region define the VW status of each node in our network analysis. 


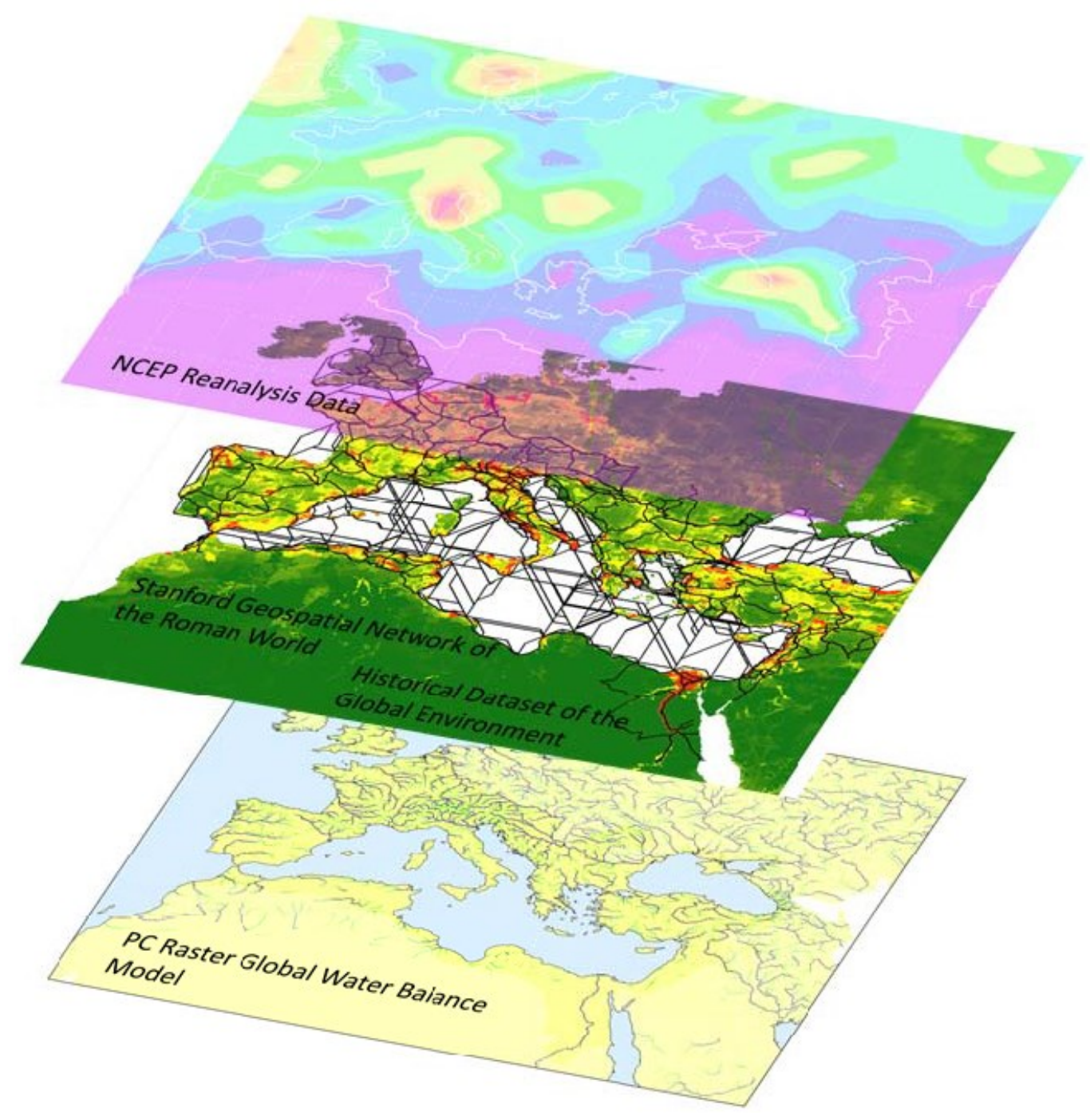

Figure S2. Virtual water network of the Roman World. Grain yields were calculated using the hydrological crop model PC Raster Global Water Balance (PCR GLOBWB) (van Beek and Bierkens, 2009; Bierkens and van Beek, 2009). PCR GLOBWB captures the heterogeneity in the hydrology of the Mediterranean region which has an important impact on the spatial heterogeneity of yields. In addition, PCR GLOBWB facilitates the calculation of crop irrigation demand based on the available surface water for irrigation. Roman agricultural land and population were assigned based on reconstructions from the History Database of the Global Environment (HYDE) (Klein Goldewijk et al., 2011). Grain yields were calculated based on NCEP daily climate forcing which allowed us to simulate the spatial and temporal heterogeneity of grain yields in response to climate. The redistribution of grain through trade was simulated using Orbis, the Stanford Geospatial Network of the Roman World as the network structure. 
A

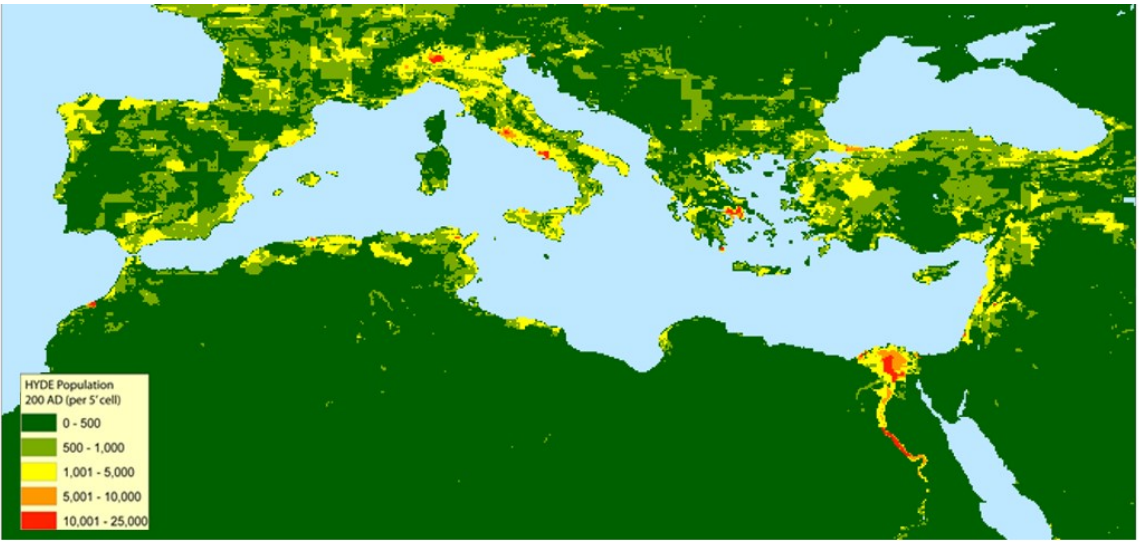

B

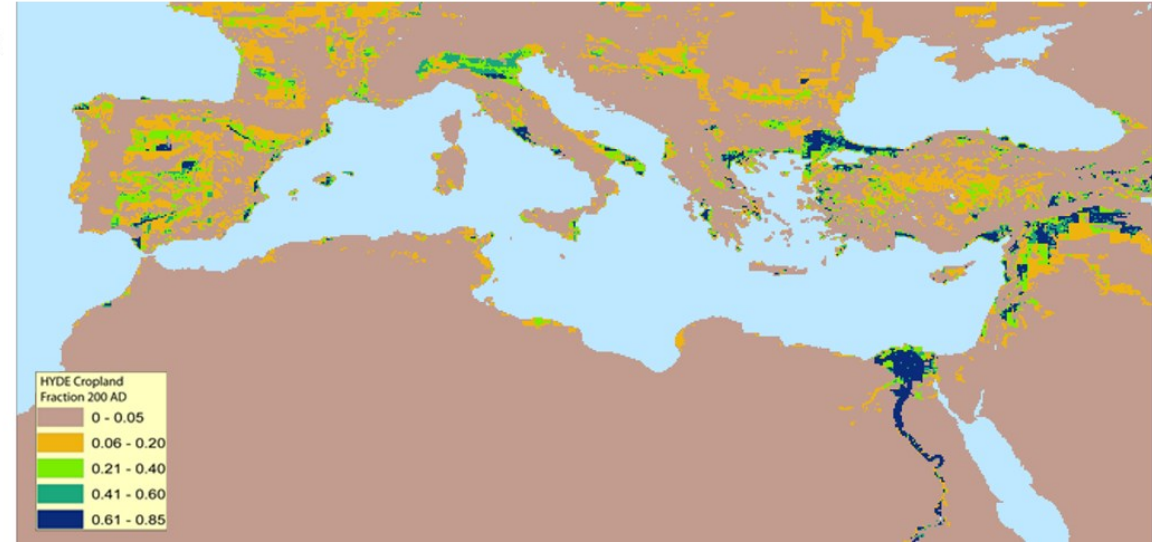

Figure S3. HYDE reconstructions of population and cropland at 200 AD. (A)

Population values are per 5' cell. (B) Cropland fractions indicate the fraction of each 5' designated as cropland. 


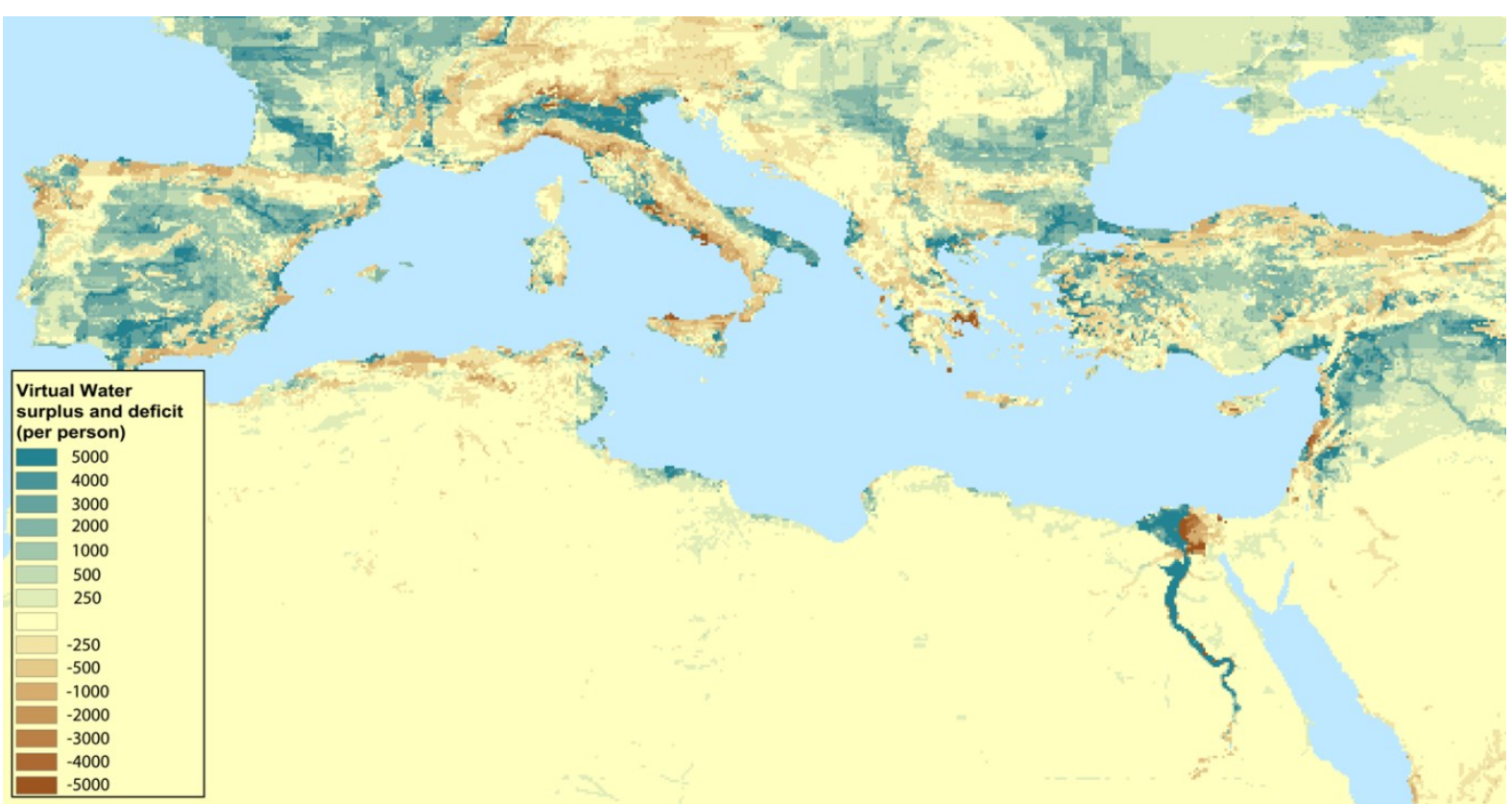

Figure S4. Virtual water surplus and deficit. The virtual water surplus and deficit measured in per person VW deficit or VW surplus is shown. The map is generated by subtracting VW demand (based on HYDE population reconstruction for $200 \mathrm{AD}$ and $200 \mathrm{~kg}$ grain per person per year) from the average annual grain yield calculated over 52 years of climate forcing. 

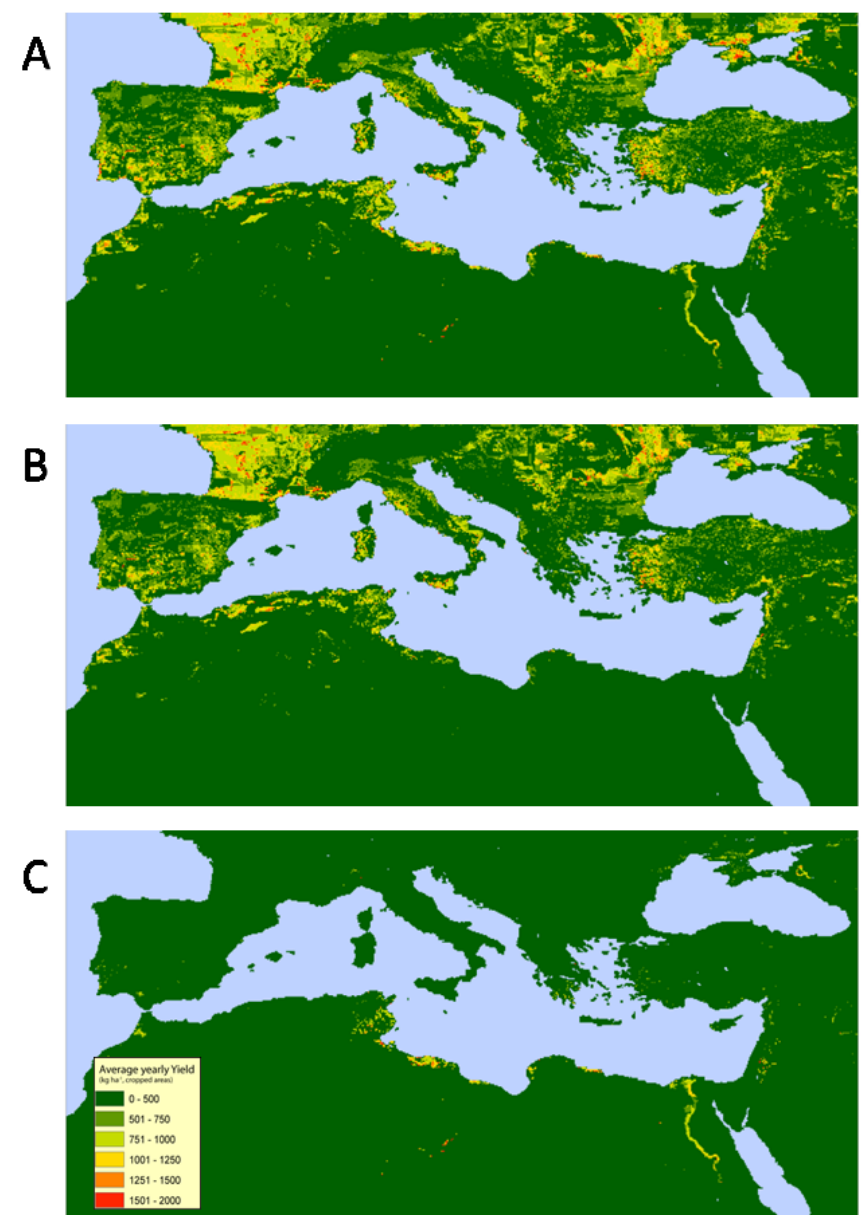

Figure S5. Average cereal yield $\left(\mathrm{kg} \mathrm{ha}^{-1}\right)$. Average cereal yield calculated in PCR GLOBWB and based on 52 years of climate forcing (A). The yields from rainfed (B) and irrigated (C) agriculture are shown separately. 

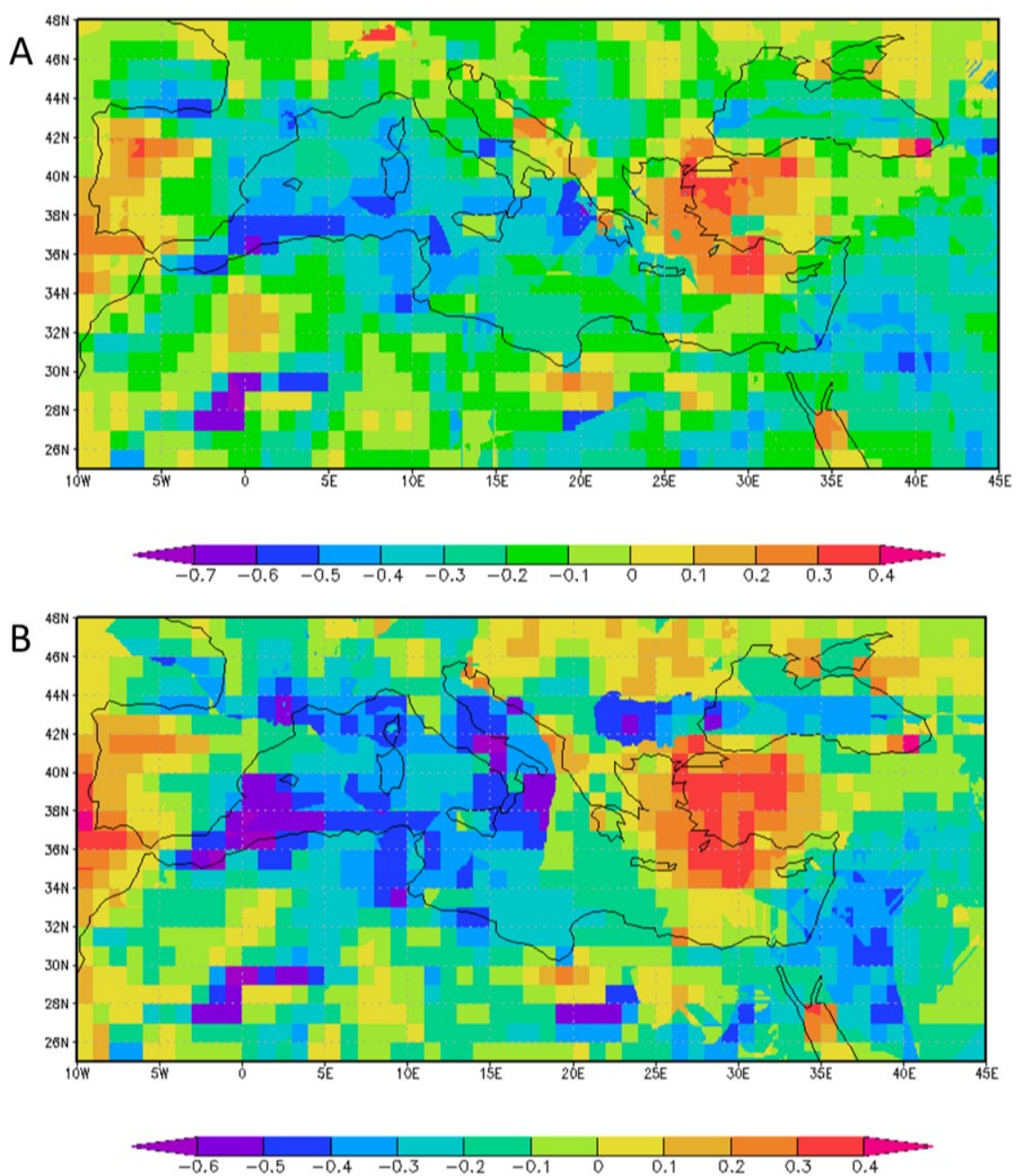

Figure S6. Correlation between temperature and precipitation over the growing season for rainfed (A) and irrigated (B) cereals. There is a negative correlation between temperature and precipitation in most of the Mediterranean apart from Western Turkey, the Western Balkans and Portugal. 

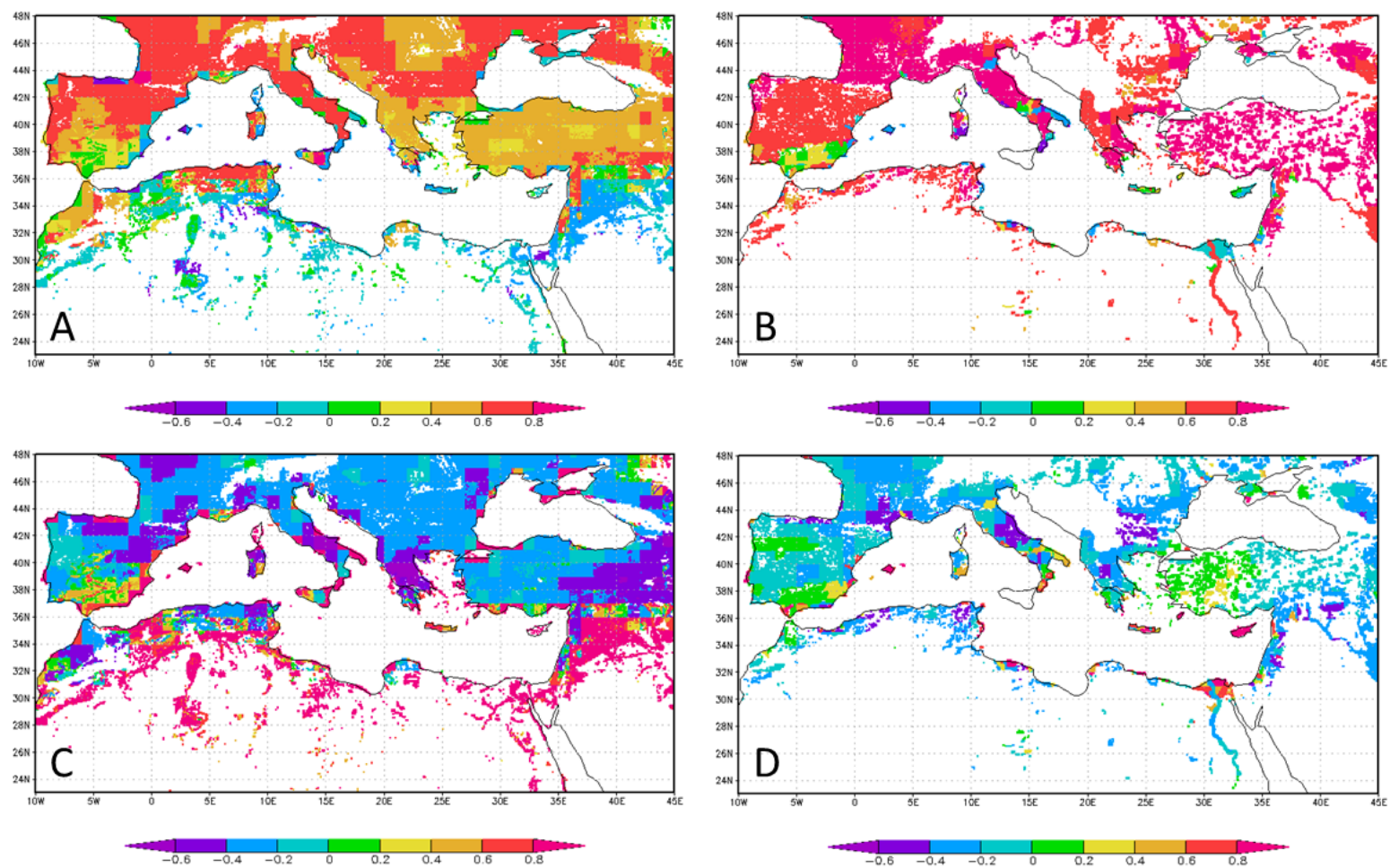

Figure S7. Correlation between temperature and precipitation over growing season with yields in rainfed and irrigated land. The correlation between temperature and yield in rainfed (A) and irrigated (B) land. The correlation between precipitation and yield in rainfed (C) and irrigated (D) land. 

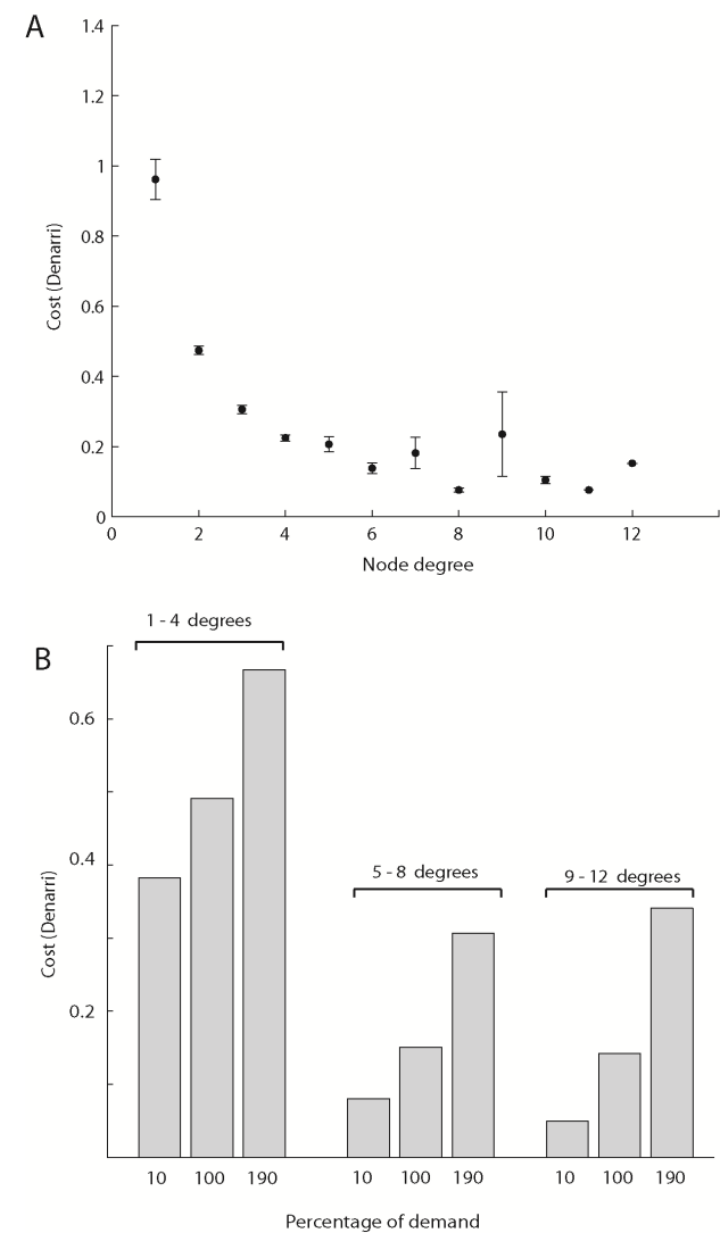

Figure S8. Cost to import VW in relation to node degree with $\mathrm{VW}$ of nodes and edge cost randomly redistributed. (A) Lower degree nodes generally have higher costs to import VW compared with high degree nodes irrespective of link cost or VW availability at the node. However certain highly connected nodes (hub nodes) have high import costs as they provide access to wider VW network for poorly connected nodes. As a result, demand at these nodes is actually the sum of demand from many nodes. Therefore nearby nodes are often depleted leading the need to import from further away with an associated increase in cost. This pattern is much stronger in the original network because a lot of hub nodes also have large populations with high demand (B) Costs increase incrementally across all node degrees for increases in demand when VW availability at nodes and edge costs are randomly distributed in the network. 